\title{
Future climate analogues of current wheat production zones in India
}

\author{
Nimisha Agarwal ${ }^{1,2, *}$ and Anindya Sinha ${ }^{1,3}$ \\ ${ }^{1}$ National Institute of Advanced Studies, Benglauru 560 012, India \\ ${ }^{2}$ Manipal Academy of Higher Education, Manipal 576 104, India \\ ${ }^{3}$ Nature Conservation Foundation, Mysuru 570 002, India
}

The future of agriculture in India will be affected by substantial changes in the environment, although not uniformly across the country. These changes, as projected by the well-known General Circulation Model will grossly impact the food-cropping system. While developing adaptation strategies, it would be useful to understand the current climatic and farming regimes in similar or analogue sites, which have already experienced future conditions. The data used in this article are from a study using the Climate Analogues tool, a web-based tool developed by the Research Programme on Climate Change, Agriculture and Food Security, which uses spatial and temporal variability in climate projections for different climatic scenarios using the General Circulation Model. Sites with statistically similar climates were thus identified and mapped; these include two sites from four different agroecological regions of wheat cropping in India. Comparisons were made specifically for the year 2030, keeping in mind changes in agricultural techniques and mechanisms that could potentially occur over a span of one and a half decades. Temperature was prioritized over other climatic variables in this study, which was conducted using the ECHAM model for the A2 scenario. A comparison of the current yields of the selected sites with those of the future analogue sites revealed the former to be at low, moderate or high risk, in accordance with the projected future climatic conditions for wheat cultivation. Most sites appeared to be at moderate risk due to temperature increase at these sites by the year 2030, and except for two sites, had significantly reduced yields.

Keywords: Climate analogue, future temperature, similar site, wheat production.

CHANGES in climate are adversely affecting agriculture ${ }^{1,2}$. It has been predicted that farming and food production systems will face substantial and distinct changes in their environments in the future. While some regions may benefit from more favourable climate conditions for production, others could face increased climate-changerelated biotic and abiotic stress ${ }^{3}$. Countries like India,

*For correspondence. (e-mail: nimisha2902@gmail.com) which are primarily based on an agricultural economy, could be worst hit by such climatic changes. This entails an urgent evaluation of risks for major food crops critical to food security ${ }^{4}$.

Global and regional projections of climate are the primary information sources ${ }^{5}$ for assessing climate change impacts. Although a consensus on the magnitude and timing of global warming may not have been established yet, current climate models do predict an average increase in temperature by $1-6.5^{\circ} \mathrm{C}$ across different regions of the earth's surface over the next century ${ }^{6}$. As suggested by Gornall et $a l^{7}$, the uncertainty in climatic projections is mainly due to 'the non-linear character of the climate system, future emissions of greenhouse gases, internal variability, model parameterization and model structural uncertainty (uncertainties in the numerical formulation of models). Internal variability leads to short-term uncertainty on the decadal time-scale whilst in addition, future emissions and model structure lead to uncertainty on the multi-decadal scale ${ }^{8}$.

This uncertainty in climate change projections is a major concern in planning adaptation measures in response to climate change and mitigating any possible negative effects. In the development and political sectors of a country like India, policy decisions for adaptation and mitigation are particularly based on projections made with the help of mechanistic models, e.g., crop response models, general circulation models, and agricultural trade models 5 . Our study focuses on wheat, the second most common staple food crop in India. Wheat is perhaps one of the most critical food crops in India and any negative impact on its growth and yield in the future would have significant repercussions on the country's food supply. Wheat grows preferentially in cooler temperatures, with early winter sowing and harvesting in early summer. Therefore, with temperatures rising towards the end of its growth, namely the grain-filling stage of development ${ }^{6}$ during summer months ${ }^{9-11}$, changes in temperature can potentially reduce wheat productivity in certain regions of its cultivation ${ }^{12}$. In a large country like India, it is very likely that the future climate of a location already exists at some other site. If such analogue locations could be identified, one can understand the possible direction of change of crop production and also learn potential 
adaptation strategies from the analogue locations. Towards this end, this study utilized the, the Climate Analogues Tool, a web-based tool developed by CCAFS (Research Program on Climate Change, Agriculture and Food Security), which identifies climate analogue locations, based on the distribution of current and future climatic data, for any reference location in the world.

The main objectives of this study are, therefore, to climatically characterize the representative centres of four important agro-climatic zones of India and to develop spatio-temporal analogues for these key representative centres of the zones.

\section{Methods}

\section{Weather downscaling}

To generate future climatic conditions, based on generalized down scaling, data generation, and keeping in mind the IPCC scenarios, MarkSim, a third-order Markov rainfall generator was used in this study ${ }^{13-15}$. Although MarkSim was not initially designed to be a General Circulation Model (GCM) down-scaler, it now works as one, employing both stochastic downscaling and weather typing over and above Type 1 downscaling.

\section{Climate analogues}

In essence, the climate analogue tool connects sites with statistically similar ('analogous') climates across space, i.e. in other geographic locations, and/or time, i.e. with historical or projected future climates. Such a tool thus helps in providing sites with both spatial and temporal similarities of climate to a specific location on the earth. In other words, the tool helps in understanding the following: (i) Where in the future would the climate of that site be similar to the current climate of a specific geographic location? (ii) Which were the sites that had similar climates in the past to the currently selected site? (iii) Where in the future would the climate of that site be similar to the past climate of a selected location?

It thus becomes possible to conduct comparative studies on potential agricultural adaptations or mitigation of negative climatic impacts between two geographically disparate sites ('spatial analogues'), the current climate of one of which is likely to be analogous to the projected future climate of another. We could also compare 'temporal analogues', in which the past historical events of one site could help us understand the possible consequences of future climate change, as also the agricultural adaptations that could prove effective at another location ${ }^{16}$.

For our current analysis, one to three representative centres in particular Indian states were chosen from four of the six agro-climatic zones of wheat production in India (Figure 1), as listed below.
(1) North Western plain zone: Ludhiana (Punjab), Delhi.

(2) North Eastern plain zone: Kanpur (Uttar Pradesh), Patna (Bihar), Ranchi (Jharkhand).

(3) Central zone: Indore (Madhya Pradesh), Kota (Rajasthan).

(4) Peninsular zone: Akola (Maharashtra).

The two hill zones, i.e. the Northern hill zone and the Southern hill zone, which have only summer production of wheat have not been chosen for this analysis, as they account for less than $5 \%$ of the total wheat production of the country.

The representative centres were chosen randomly from amongst a pool of wheat-growing centres in each of the agro-climatic zones, wherein wheat cultivation experiments have been conducted previously and from which, therefore, data could be obtained on wheat productivity and yields, and on other bioclimatic factors that could potentially affect its growth.

The climatic characterization of the representative centres was conducted in accordance with wheat phenology. Climatic risk was also estimated for these centres by estimating relevant parameters such as thermal time, growing degree days, maximum temperature and minimum temperature.

In order to understand shifts in climatic conditions, the MarkSim tool was used to generate future climatic regimes, in accordance with different GCM model and IPCC emission scenarios. The A2 scenario ${ }^{17,18}$ was taken into account, assuming that India, being a developing country, was following a heterogeneous path of economic development. The GCM models considered were those of ECHAM and CSIRO, as these have yielded better results than agriculture simulation models in previous studies ${ }^{19}$.

Subsequent to the estimation of climatic risks and expected shifts in daily temperature range after a period of approximately 30 years, the Climate Analogue Tool was used to obtain temporal analogues of the representative centres. The ECHAM 5.0 model $^{20}$ has yielded more successful results in previous studies over the CSIRO MK3.0 model in predictions that have used temperature as the determining factor ${ }^{21}$. Therefore, the latter model was not employed in this study. The climate analogues tool can be designed for specific results as shown in Figure 2, but for the purpose of this study, the parameters listed below were considered.

- Analysis for dissimilarity: Grid-based dissimilarity analysis: one single location is compared with entire geographic domain.

- Method for dissimilarity: CCAFS.

- Climatic zone: Regional.

- SRES: A2 scenario.

- GCM TARGET: ECHAM 5.0 model was selected for the current study for the year 2030 .

- Variable: Climatic: Mean temperature, rainfall. 
RESEARCH ARTICLES
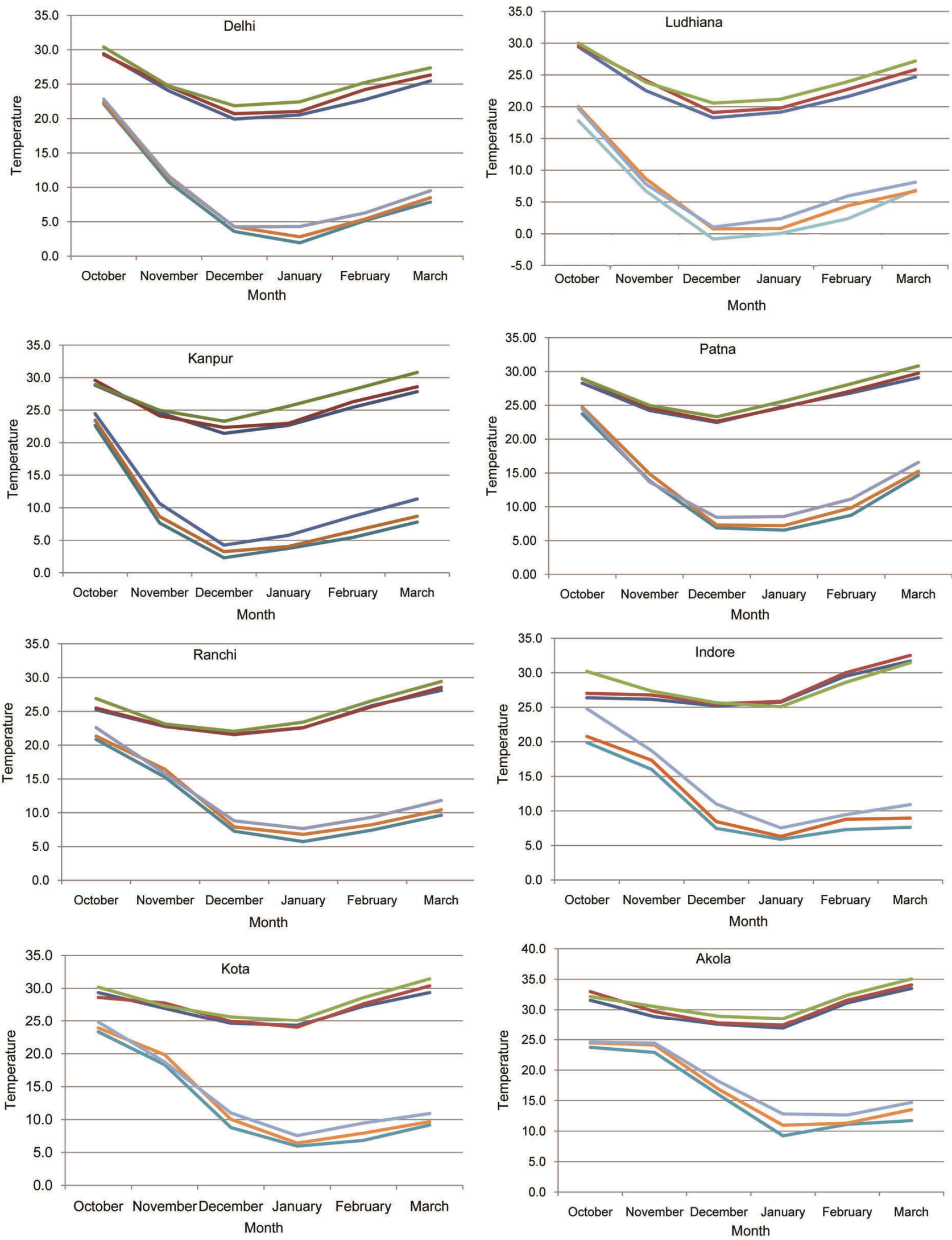

$-\boldsymbol{T}_{\max }$ (2010) $-\boldsymbol{T}_{\max }(2030)-T_{\max }(2050)-T_{\min }(2010)-T_{\min }(2030)-T_{\min }(2050)$

Figure 1. Change in maximum temperature $\left(T_{\max }\right)$ and minimum temperature $\left(T_{\min }\right)$ for years $2030,2050,2080$ for the various selected sites. 


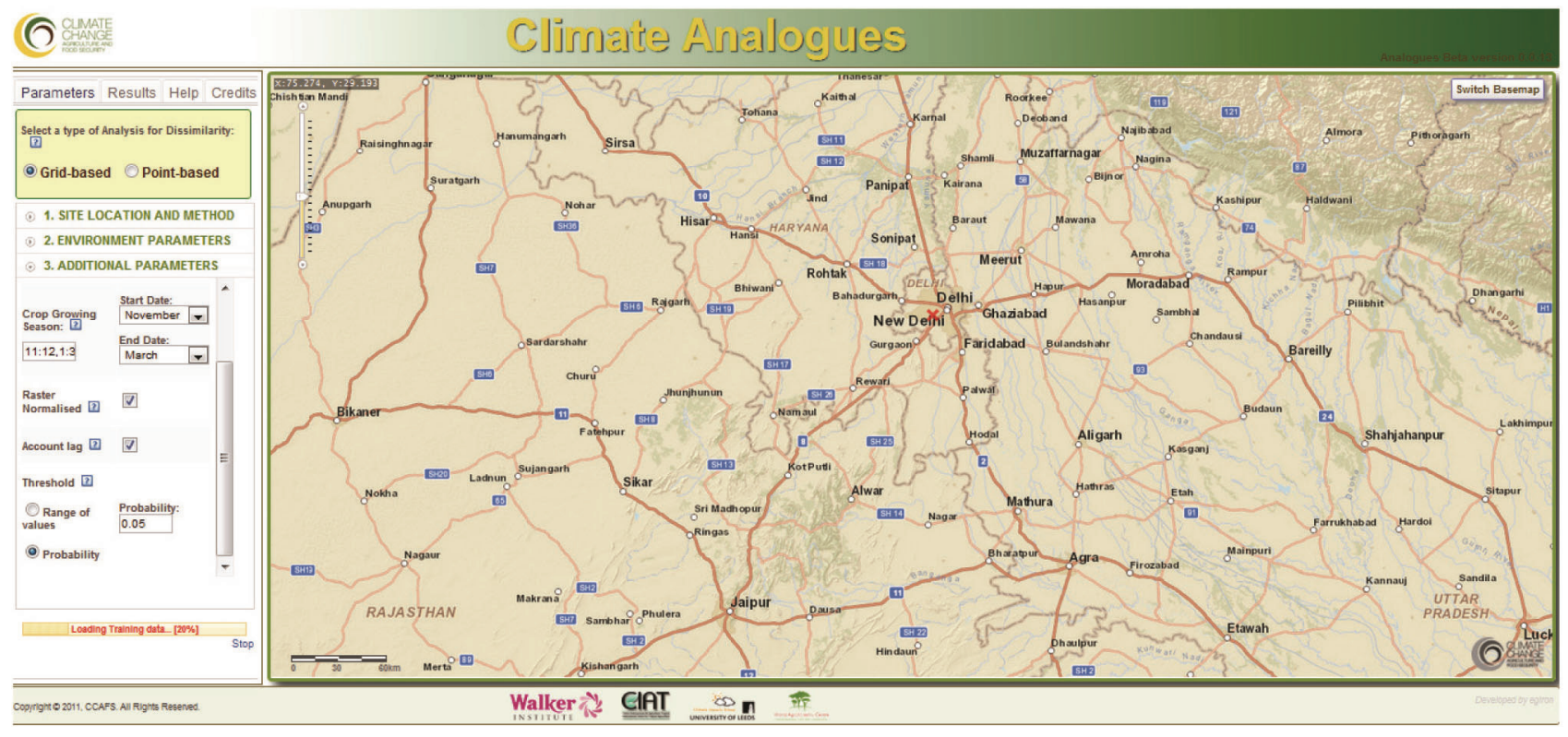

Figure 2. Climate analogue input.

- Weight: Relative importance to be given to parameters selected for analysis.

- Direction: Backward: would use future climate as reference and give analogue in reference to current climate.

- Crop growing season: In case of wheat variety growing season was taken as November-March.

The Climate Analogues Tool was run in the CCAFS mode of dissimilarity, using specific parameter values of global region, A2 scenario, MPI ECHAM 5.0, climatic factor with temperature being the parameter of choice, diurnal temperature range and in the backward direction.

Finally, the results that were obtained from the Climate Analogues Tool were analysed further using the DIVAGIS software ${ }^{22}$. Administrative boundaries were added using data from the Gazetteer of India ${ }^{22}$. High probability zones of climatic similarity were identified and marked and the same converted into user-friendly formatted data for further analyses result as shown in Figure 3.

\section{Results}

\section{Climatic risk}

Climate risk levels for the various selected sites have been shown in Table 1. Risk levels are usually determined by the number of days with temperatures higher or lower than the optimum maximum and minimum temperatures.

Delhi, according to its current climatic condition, has negligible risks and Patna has a high risk for wheat pro- duction. Ludhiana and Ranchi have moderate risks for climatic changes based on number of days beyond the optimum range. In the current situation, the high-risk regions would lose out on yields, as compared to the lowrisk regions. Climatic change can alter the suitability of a geographic area for crops that are typically grown there, leading to possible changes in the type and extent of crops that can be grown in those areas as mentioned in Table 1 (ref. 23).

According to Figure 1, Delhi will not experience a drastic change in average maximum temperature by 2030; however the change in average minimum temperature is expected to be significant, almost $0.75^{\circ} \mathrm{C}$ higher over most of the crop-growing season. In a nutshell, the nights are going to be warmer while the months of February and March would see little difference in temperatures. Ludhiana, on the other hand, is expected to see significant changes in both maximum and minimum average temperature by 2030 , with an approximate increase of an average of $0.75^{\circ} \mathrm{C}$.

The expected climate change for Kanpur is minimal, as the maximum temperatures are expected to remain similar except for a minor increase of around $0.25^{\circ} \mathrm{C}$ in the months of February and March, while the minimum temperatures are expected to increase in months of November and December. Temperatures however, are expected to rise steeply after 2030 and the variations then are expected to be much higher compared to current changes.

In Patna, the temperature changes are expected to remain as they are, with a slight trend towards an increase in minimum temperatures (up to $0.20^{\circ} \mathrm{C}$ ). However, changes in minimum temperatures in December are 


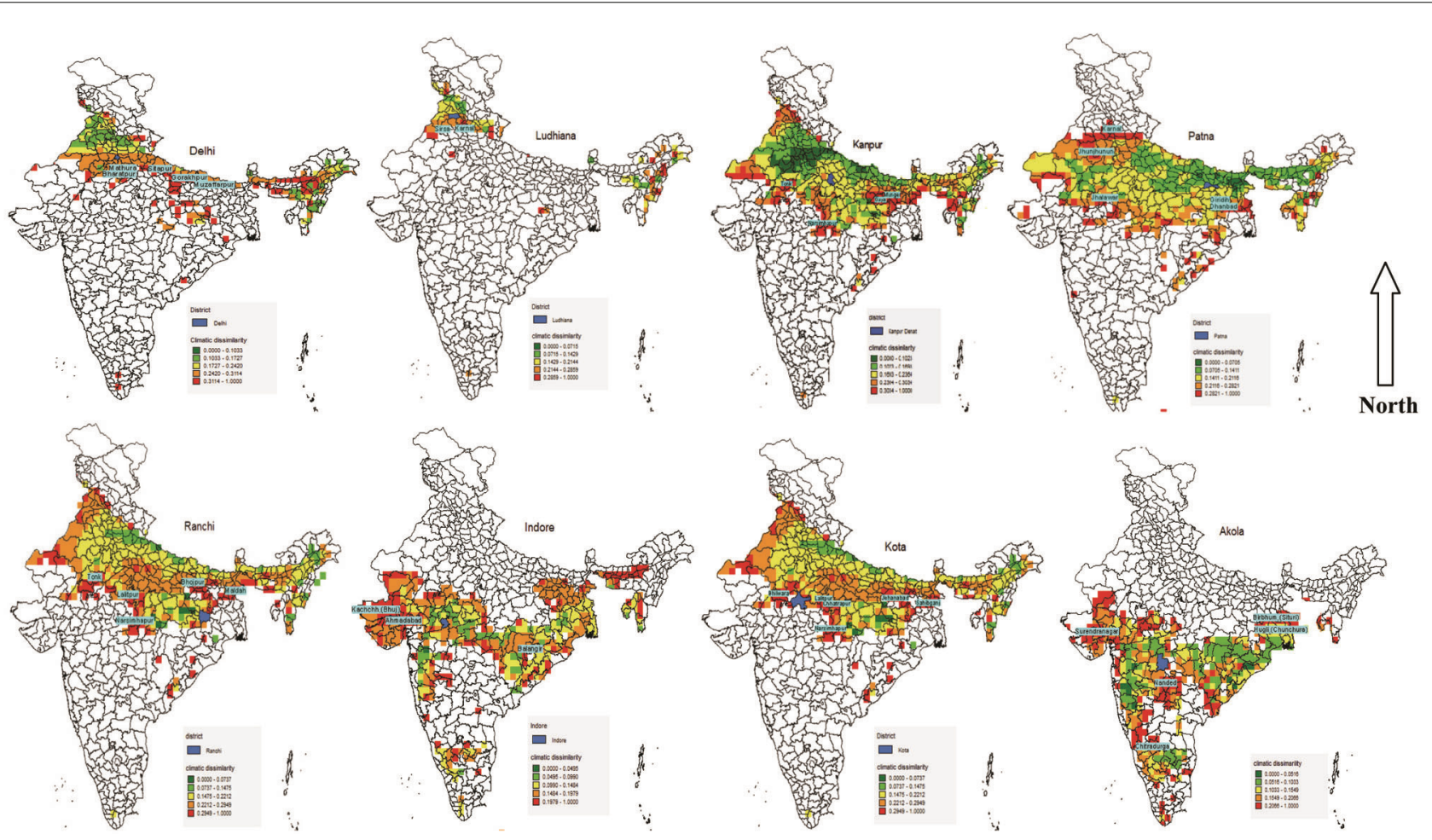

Figure 3. Analogue sites for various wheat growing centres in India.

Table 1. Analysis of climatic risk for the selected sites

\begin{tabular}{lcccc}
\hline Site & $T_{\max }>30\left({ }^{\circ} \mathrm{C}\right)$ & $T_{\min }<5\left({ }^{\circ} \mathrm{C}\right)$ & Growing degree days & $T_{\mathrm{m}}\left({ }^{\circ} \mathrm{C}\right)$ \\
\hline Delhi & 2 & 0 & 2212 & 16.4 \\
Ludhiana & 1 & 10 & 2003 & 14.8 \\
Kanpur & 11 & 1 & 2309 & 17.1 \\
Patna & 14 & 0 & 2525 & 18.7 \\
Ranchi & 6 & 0 & 2449 & 18.1 \\
& $T_{\max }>35\left({ }^{\circ} \mathrm{C}\right)$ & $T_{\min }<10\left({ }^{\circ} \mathrm{C}\right)$ & Growing degree days & $T_{\mathrm{m}}\left({ }^{\circ} \mathrm{C}\right)$ \\
Akola & 1 & 1 & 2664 & 22.2 \\
\hline
\end{tabular}

expected to remain comparable to that current by the year 2030.

In the central region, Indore is likely to have decidedly different temperature patterns compared to the North West plain and North East plain zones. Temperatures would be higher in the month of November but almost no observable change is expected in the maximum temperatures in the area. On the other hand, minimum temperatures are expected to have small changes, in January and November, with an increase of almost $0.5^{\circ} \mathrm{C}$. Thus, this area will display significant increase in minimum temperature but negligible increase in maximum temperature. This trend is foreseen until 2050 and subsequently through 2080 .

In western India, Kota will see changes in both maximum and minimum average temperatures by the turn of the decade $\left(0.75^{\circ} \mathrm{C}\right)$. Much like Ranchi, significant change is predicted post 2050. Akola, falling in the Vidarbha region, follows a different climatic trend. Here, the points of comparison are areas identified in the North Western plain zone and North Eastern plain zone. November and January would see a steep temperature drop and except in October and November, the area would not experience overall changes in the maximum temperatures. Like most other areas, until 2030, temperature changes are likely to be minimal to insignificant here, and after that, there would be marginal changes. It is only after 2080 that there may be drastic changes in the area.

\section{Climatic analogues for various sites}

If we were to examine the sites in northern India, Delhi and Kanpur have a wide spectrum of analogue sites, but 
RESEARCH ARTICLES

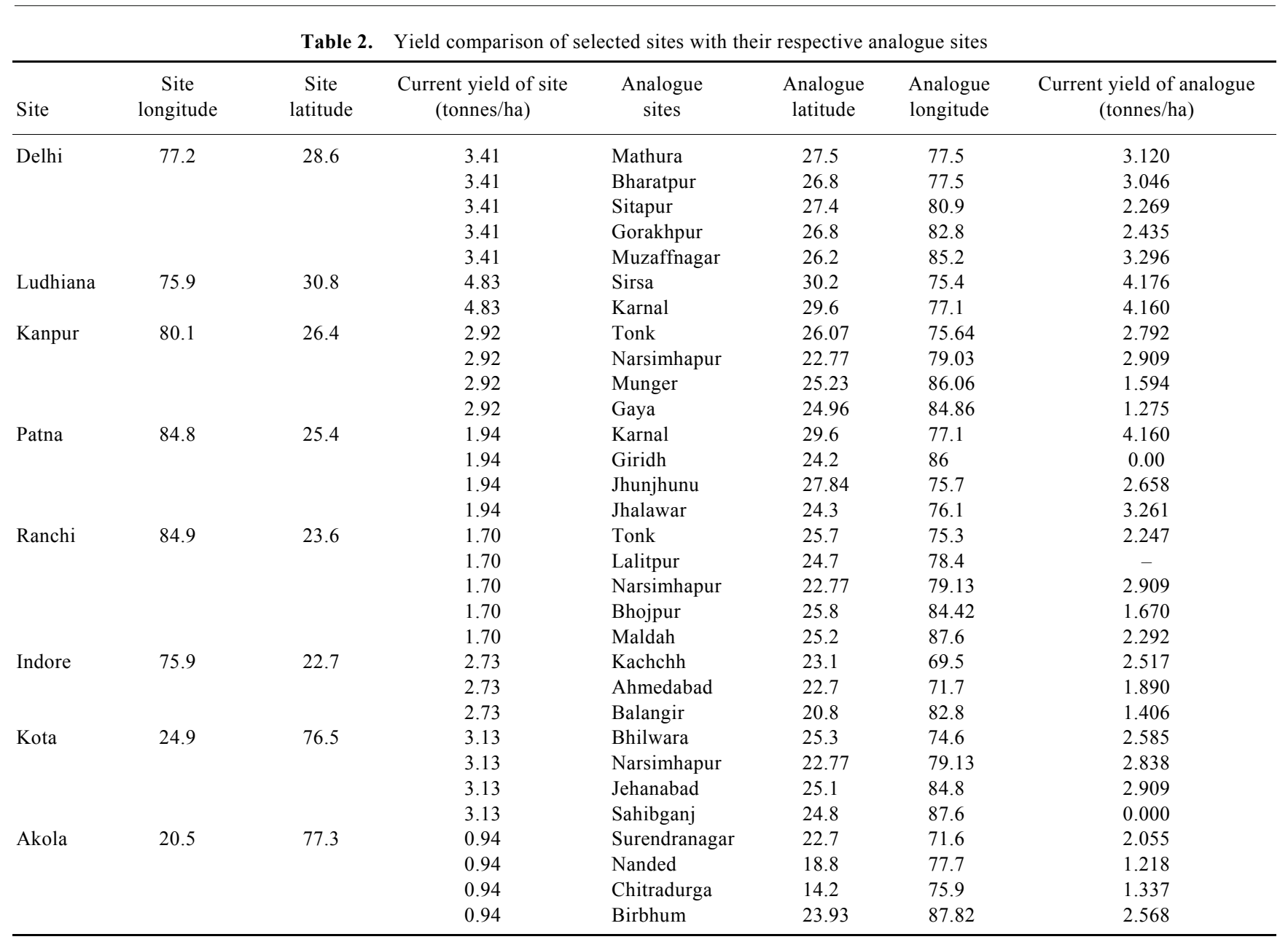

not Ludhiana. Ludhiana would have temperature conditions similar to some parts of northeast India and certain areas in the near vicinity of its current location, such as Haryana and Himachal Pradesh as shown in Figure 3.

Analogue sites for Ludhiana lie approximately in the same latitude with only a minor longitudinal shift and thus, they currently have similar yields, as compared to the site location itself, with minor deterioration in its values. In the future, Ludhiana is expected to have a slight reduction in wheat yields with changes in climate as mentioned in Table 2. The changes expected are not significant and so likely to be overcome by slight alterations in the sowing season or certain agricultural innovations in order to have wheat production similar to the current situation. Delhi on the other hand, is expected to have several centres with similar climate although highprobability regions are not as many. Delhi's climate is expected to change slightly, resembling places at lower latitudes and moderate change in the surrounding regions. However, if Delhi's climatic conditions follow the predicted analogue, a significant reduction in yield is expected in future years. This is because most of its analogue sites are on $26^{\circ} \mathrm{N}$ latitude, which is almost a $2^{\circ}$ latitude shift from its current position and have lower wheat yields than Delhi itself, with analogue sites like Gorakhpur and Muzaffarnagar having significantly lower yields.

Similarly, in Kanpur, despite a wide spread of analogue sites, a generalized trend of reduction in yield is expected, except in the analogue site of Narsimhapur. Analogue sites like Gaya have half the current wheat production of Kanpur. Expected yield losses such as these would require a lot of deliberation about dealing with temperature changes in the near future so as to avoid losses in wheat production. Location-wise, the analogue sites of Kanpur region occur with an average latitudinal shift of $2-4^{\circ} \mathrm{S}$ but with a significant shift in longitudes stretched across the Indian subcontinent. Centres with high dissimilarity are present across the country in the states of Rajasthan, Madhya Pradesh, Bihar, and parts of West Bengal and northeast India. A few grids in Odisha also show a climatic dissimilarity with the current conditions.

In the east, both Ranchi and Patna are expected to have a large number of analogue sites. While Ranchi has analogue sites present all across northern India, with highprobability regions present mostly in central India and 
medium-probability regions in Rajasthan, most of Patna's analogue sites lie in the states of Haryana and Rajasthan, with relatively fewer high-probability regions than Ranchi. Patna is also expected to have analogue sites both above and below its current latitudinal position with a longitudinal shift westward of its current location.

Moving to central India, we find that the analogue sites for both Indore and Akola are patchy and not like the North Western plain region. While Indore's analogue sites are spread across the central region of the country with a few sites in the peninsular region and in northeastern India, Akola has an inconsistent representation with the future climatic conditions in the peninsular region of the country, wherein lie a few patches of similar conditions, but with most of the sites closer to the coastal area. In the future, Indore is expected to have analogue sites mostly in the state of Gujarat. Ahmedabad lies on the same latitude as Indore while Kachhch is above it and Balangir is below in their latitudinal positions. Indore would face longitudinal shifts to both the east and west while Akola is expected to have both significant latitudinal and longitudinal shifts. In terms of yield, Indore has higher wheat production than its analogue sites, while it is the reverse in the case of Akola. Thus, our results indicate a negative change in wheat production in the Indore region and an increased yield in Akola in response to change of climate according to the predicted scenarios.

\section{Discussion and conclusions}

Temperature is the most important factor among all other climatic parameters in determining plant growth and development, and therefore, largely impacts agricultural productivity. It is thus crucial to generate models that can summarize such impacts, and simulations of the responses that plant growth and development exhibit to changes in temperature regimes need to be examined urgently ${ }^{24}$. Hence, the knowledge of the optimum temperature conditions for the growth of a particular genotype is fundamentally important to the successful prediction of its maturity, adaptation and yield in a particular environment ${ }^{25}$.

Our comparisons were made specifically for the year 2030, keeping in mind the changes in agricultural techniques and mechanisms that are likely to occur within the next 20 to 30 years. While it is imperative to study these changes in climate regimes overall, our study particularly considered temperature alone. For a more comprehensive understanding, we should perhaps consider other factors such as rainfall, soil type, fertilizers and other possible or probable future agricultural innovations.

It is also important to recognize the limitations and consequently, the appropriate application of the Climate Analogues Tool. The dissimilarity measures that can potentially be developed can be agriculturally meaningful if they can be related to adaptation practices by farmers or in terms of understanding actual crop yields ${ }^{16}$. For example, the tool can analyse results based only on climatic conditions whereas, the performance of any crop is also governed by its environment, including the application of fertilizers, irrigation, and the variety of crops grown. These factors have, however, not been considered in the analysis of this paper. There is an inherent limitation of computational models in determining the exact nature of human responses in a particular location ${ }^{26}$, although a study could often attempt to use the best predicted economic scenario in order to account for human responses. In this case, since all the districts are in the Indian subcontinent, socio-economic extrapolation and policy changes are similar and therefore analogue sites would be reflective of the same.

Irrespective of the many assumptions and uncertainties associated with oft-used crop and climate models, several analyses have pointed to the impacts of climate change on food security ${ }^{5}$. Adaptation to climatic change would be a key factor that is likely to shape the future severity of climate change impacts on food production. Such adaptations would require substantial investments by farmers, governments, scientists and development organizations, all of whom face many other demands on their resources. The prioritization of investment needs, such as through the identification of climate risk hot spots $^{27}$ is, therefore, a critical issue but has received limited attention to date in the literature. Not only does the analogue tool provide a new finding to map these hot spots, it can also be used to find the current climate hotspots using the forward direction analyses.

We believe that the Analogue Tool may have better applications in the social science fieldwork, e.g. by connecting farmers to their possible climate futures via farm visits. Hence, farmers would not only be able to envision how their site-specific agricultural future might look, but also potentially put into practice the new adaptive strategies that they may witness first-hand ${ }^{13}$. Learning from one site, in terms of understanding the coping mechanism from a region, may better equip other regions in the country. The peer to peer learning of farmers can be envisioned as a potential method of adaptation for farmers, especially marginal and small farmers, who may not rely heavily on technological adaptations, and rather more on change in farming practice.

1. Masutomi, Y., Takahashi, K., Harasawa, H. and Matsuoka, Y., Impact assessment of climate change on rice production in Asia in comprehensive consideration of process/parameter uncertainty in general circulation models. Agric. Ecosyst. Environ., 2009, 131, 281-291.

2. Jayaraman, T. and Murari, K., Climate change and agriculture: current and future trends and implications for India. Rev. Agrar. Stud., 2014, 130, 1-49. 


\section{RESEARCH ARTICLES}

3. Srivastava, P., Singh, R., Tripathi, S. and Raghubanshi, A. S., An urgent need for sustainable thinking in agriculture - an Indian scenario. Ecol. Indic., 2016, 67, 611-622.

4. Brown, M. E. and Funk, C. C., Climate. Food security under climate change. Science, 2008, 319, 580-581.

5. Challinor, A. J. and Wheeler, T. R., Crop yield reduction in the tropics under climate change: Processes and uncertainties. Agric. For. Meteorol., 2008, 148, 343-356.

6. Krishnan, P. et al., Web-based crop model: Web InfoCropWheat to simulate the growth and yield of wheat. Comput. Electron. Agric., 2016, 127, 324-335.

7. Gornall, J. et al., Implications of climate change for agricultural productivity in the early twenty-first century. Philos. Trans. $R$. Soc., London B, Biol. Sci., 2010, 365, 2973-2989.

8. Biemans, H. et al., Report on Intercomparison of the relative performance of the three modelling approaches (D2.4), High Noon Delivery Report, 2012.

9. Harding, S. A., Guikema, J. A. and Paulsen, G. M., Photosynthetic decline from high temperature stress during maturation of wheat 1 . Interaction with senescence processes. Plant Physiol., 1990, 92, 648-653.

10. White, J. W., Modeling temperature response in wheat and maize. Proc. a Work. CIMMYT, El Batán, Mex. 23-25 April 2001, 2003, pp. 1-61.

11. Wang, Y., Handoko, J. and Rimmington, G., Sensitivity of wheat growth to increased air temperature for different scenarios of ambient $\mathrm{CO}_{2}$ concentration and rainfall in Victoria, Australia - a simulation study. Clim. Res., 1992, 2, 131-149.

12. Ortiz, R. et al., Climate change: Can wheat beat the heat? Agric. Ecosyst. Environ., 2008, 126, 46-58.

13. Jones, P. and Thornton, P., A rainfall generator for agricultural applications in the tropics. Agric. Forest Meteorol., 1993, 63, 1-19.

14. Jones, P. and Thornton, P., Spatial and temporal variability of rainfall related to a third-order Markov model. Agric. Forest Meteorol., 1997, 86, 127-138.

15. Jones, P. and Thornton, P., Fitting a third-order Markov rainfall model to interpolated climate surfaces. Agric. Forest Meteorol., 1999, 97, 213-231.

16. Ramírez-Villegas, J. et al., Climate Analogues, 2011.

17. Valizadeh, J., Ziaei, S. M. and Mazloumzadeh, S. M., Assessing climate change impacts on wheat production (a case study). $J$. Saudi Soc. Agric. Sci., 2014, 13, 107-115.

18. IPCC. IPCC Fourth Assessment Report: Climate Change 2007. Agricultural and Forest Meteorology, 2007, 87.

19. Samadi, S. Z., Sagareswar, G. and Tajiki, M., Comparison of general circulation models: methodology for selecting the best
GCM in Kermanshah Synoptic Station, Iran. Int. J. Global Warm, 2010, 2, 347.

20. Jones, P., Thornton, P. and Heinke, J., Generating characteristic daily weather data using downscaled climate model data from the IPCC's Fourth Assessment. Project Report. International Livestock Research Institute, 2009, 24.

21. Milne, M., Godden, D., Kennedy, J. and Kambuou, R., Evaluation the benefits of conserved crop germplasm in PNG. In Managing Plant Genetic Diversity, Australian Agricultural and Resources Economics Society, 1999, vol. 43, pp. 2-30.

22. Bessadok, A., Roudesli, S., Marais, S., Follain, N. and Lebrun, L., Alfa fibres for unsaturated polyester composites reinforcement: Effects of chemical treatments on mechanical and permeation properties. Compos. Part A: Appl. Sci. Manuf., 2009, 40, 184-195.

23. Adams, R. M., Hurd, B. H., Lenhart, S. and Leary, N., Effects of global climate change on agriculture: an interpretative review. Clim. Res., 1998, 11, 19-30.

24. McMaster, G. S. et al., Simulating the influence of vernalization, photoperiod and optimum temperature on wheat developmental rates. Ann. Bot., 2008, 102, 561-569.

25. He, Z., Joshi, A. K. and Zhang, W., In Climate Vulnerability: Understanding and Addressing Threats to Essential Resources (ed. Roger Pielke), Academic Press, 2013, vol. 2, pp. 57-67.

26. Lobell, D. B., Schlenker, W. and Costa-Roberts, J., Climate trends and global crop production since 1980. Science, 2011, 333, 616620 .

27. De Souza, K. et al., Vulnerability to climate change in three hot spots in Africa and Asia: key issues for policy-relevant adaptation and resilience-building research. Reg. Environ. Chang., 2015, 15, $747-753$.

ACKNOWLEDGEMENTS. Some sections of this paper form part of Nimisha Agarwal's dissertation, conducted under the supervision of Prammod Agarwal and submitted to the Department of Environmental Sciences, University of Delhi, for the award of a Master's degree. A special note of gratitude is due to Prem Mathur of Biodiversity International, Department of Environmental Sciences, Indian Agricultural Research Institute, Delhi for providing the necessary data and other support during the course of this study.

Received 20 August 2017; revised accepted 11 September 2018

doi: $10.18520 / \mathrm{cs} / \mathrm{v} 116 / \mathrm{i} 2 / 264-271$ 